Research Article

\title{
Study of GLR and Inlet Velocity on Hydrocyclone for Fracturing Flow-Back Fluids
}

\author{
Bing Liu (D), ${ }^{1}$ Huajian Wang, ${ }^{1}$ Luncao Li, ${ }^{1}$ Zhenjiang Zhao, ${ }^{1}$ Liping Xu, ${ }^{1}$ and Jianliang Xue ${ }^{2}$ \\ ${ }^{1}$ College of Mechanical and Electrical Engineering, Shandong University of Science and Technology, \\ Qingdao, Shandong 266590, China \\ ${ }^{2}$ College of Chemical and Environmental Engineering, Shandong University of Science and Technology, Qingdao 266590, China
}

Correspondence should be addressed to Bing Liu; skdpaper2008@163.com

Received 12 June 2019; Revised 8 August 2019; Accepted 23 August 2019; Published 12 September 2019

Academic Editor: Luis M. López-Ochoa

Copyright (c) 2019 Bing Liu et al. This is an open access article distributed under the Creative Commons Attribution License, which permits unrestricted use, distribution, and reproduction in any medium, provided the original work is properly cited.

\begin{abstract}
In this work, based on the Reynolds stress model (RSM) of the computational fluid dynamics (CFD) software Fluent and experimental method, the velocity field, pressure characteristics, split ratio, and separation efficiency of the hydrocyclone are analyzed under different gas-liquid ratios (GLRs). For the inlet velocity, the lower limit is ascertained by the flow field stability, the upper limit is largely determined by the energy consumption, and the optimum range is $4 \mathrm{~m} / \mathrm{s}$ to $10 \mathrm{~m} / \mathrm{s}$. Within the optimum range, the peak value of tangential velocity increases while the GLR increases, whereas the pressure and pressure drop decrease. With the increase in the GLR, the axial velocity decreases, and the locus of zero vertical velocity shifts inward. The increase in the GLR causes more gas to collect at the vortex finder, which hinders the discharge of the solid-liquid mixture from the overflow, and the larger the GLR, the faster the decrease in the split ratio. The separation efficiency of particles with a particle size of $15 \mu \mathrm{m}$ is increased by $6.75 \%$, and the separation efficiency of particles with a particle size of $30 \mu \mathrm{m}$ is increased by $0.57 \%$. Meanwhile, the separation efficiency is increased by $2.43 \%$, and the cut size $\left(\mathrm{d}_{50}\right)$ is reduced as the GLR increases.
\end{abstract}

\section{Introduction}

Hydraulic fracturing is the main way of increasing the production of shale gas reservoirs, but the water and air would be polluted by fracturing, so the fracturing flow-back fluids needs to be treated to meet the requirements of discharge and reinjection $[1,2]$. Before chemical treatment, in order to avoid the abrasion of pipes and other equipment by high-speed flowing particles, the particles should be removed $[3,4]$. Hydrocyclones are widely used in petrochemical industry to separate particles from fracturing flowback fluids because of the advantages of ease of operation, design simplicity, and maintenance costs $[5,6]$. In order to achieve the cyclonic separation of the fracturing flow-back fluids, the selection of the hydrocyclone is generally based on general theoretical, empirical, and semiempirical formulas or the Krebs method [7-9]. However, because of the complexity of the flow pattern of the internal flow field and the unfixed parameters, it is difficult to achieve the desired separation effect. Because of the complex composition of the fracturing flow-back fluids, the characteristics of gas carrying makes the internal flow field more complicated [10]. Therefore, it is necessary to study the internal flow field and external characteristics under different GLRs and to achieve the requirement of efficient separation.

The inlet velocity of the hydrocyclone is important, which affects the internal flow field and external characteristics of the hydrocyclone such as velocity, pressure, and split ratio [11], as determining the upper and lower limits of the inlet velocity of hydrocyclone can reduce energy consumption and improve separation efficiency. The upper and lower limits of the inlet velocity of the same hydrocyclone will be different under different physical parameters. Rietema suggested that the lower limits of the inlet velocity is determined by static pressure loss and the upper limits of the inlet velocity is determined by the centrifugal head [12], and many experiments have determined the maximum limit with respect to the separation efficiency $[13,14]$. In recent 
years, Zhang et al. suggested that the lower limit is ascertained by the flow field stability and the upper limit is largely determined by the energy consumption [15]. In this paper, by combining the above research contents, the stability of the internal flow field is determined by the stability of the air core. The lower limit of the inlet velocity is obtained, and the upper limit of the inlet velocity is determined by the degree of change of the tangential velocity.

Relative to the inlet velocity, GLR will also have an important effect on the separation characteristics of the hydrocyclone for fracturing flow-back fluids. Chu et al. studied the pressure distribution, stress of particles, and velocity of the internal flow field of the hydrocyclone by injecting the gas from the side wall, but did not analyze the internal flow field and external characteristics under different GLRs $[16,17]$. Zhao et al. suggested that the efficiency of separation of oil-water hydrocyclones can be improved by injecting the gas into the inlet and side walls [18]. The GLR will affect the internal flow field while studying the three-phase hydrocyclone, which improves the separation efficiency of sand. But the structure is quite different from the traditional hydrocyclone, which does not provide reliable guidance for the optimization research of the traditional hydrocyclone $[19,20]$. Miller suggested that an air-sparged hydrocyclone (ASH) can improve flotation efficiency of fine particles and gases in the mixture, but the distribution of the internal flow field is not studied systematically [21]. Nonaka found that the inlet flow rate of air has effect on the flotation recovery and the flotation rate constant, but the influence of the GLR on the internal flow field is not studied [22].

In this study, the relative optimum inlet velocity range was studied by flow patterns and equation models (FP-EM) [15], and the separation characteristics under different GLRs for the fracturing flow-back fluids of shale gas were discussed, so as to provide technical guidance for the optimization of hydrocyclones under similar conditions. The characteristics of the internal flow field and external flow field of the hydrocyclone were studied by CFD software Fluent and experimental method. The simulation process is as follows. The air and water are simulated by RSM + mixture firstly, and the flow field of the hydrocyclone at different inlet velocities is obtained, and the optimum range of inlet velocity under this condition is determined. The second step is to simulate water, air, and sand under different GLRs by RSM + mixture in the optimum range inlet velocity, so as to study the influence of GLR on the internal flow field of the hydrocyclone. Finally, the external characteristics are studied by experimental methods, and the experimental values are compared with the simulated values. The method and result of research can provide guidance for the study of the hydrocyclone under similar conditions.

\section{Numerical Simulation Method}

With the development of computational fluid dynamics, numerical simulation has been applied to the analysis and prediction of internal flow fields $[23,24]$. Because the
Reynolds stress model (RSM) and the mixture model are widely used in the numerical simulation of the hydrocyclone, and the accuracy of the model are verified by a large number of documents $[22,25]$, the details of the RSM and mixture model have been well explained elsewhere [26, 27]. In this study, the key features of the RSM and mixture model are as follows.

\subsection{Reynolds Stress Model (RSM)}

$$
\frac{\partial\left(\rho \overline{u_{i}^{\prime} u_{j}^{\prime}}\right)}{\partial t}+\frac{\partial\left(\rho u_{k} \overline{u_{i}^{\prime} u_{j}^{\prime}}\right)}{\partial x_{k}}=D_{l, i j}+P_{i j}+\varphi_{i j}+\varepsilon_{i j},
$$

where $D_{l, i j}$ is the turbulent diffusion, $P_{i j}$ is the stress production, $\varphi_{i j}$ is the pressure strain, and $\varepsilon_{i j}$ is the dissipation.

\subsection{Mixture Model}

$$
\begin{aligned}
\frac{\partial}{\partial t}\left(\rho_{m}\right)+\frac{\partial}{\partial x_{i}}\left(\rho_{m} u_{m}\right)= & 0, \\
\frac{\partial}{\partial t} \rho_{m} u_{m i}+\frac{\partial}{\partial x_{j}} \rho_{m} u_{m i} u_{m j}= & -\frac{\partial P}{\partial x_{i}}+\frac{\partial P_{s, \text { total }}}{\partial x_{i}} \\
& +\frac{\partial}{\partial x_{j}}\left[\mu_{m}\left(\frac{\partial u_{m i}}{\partial x_{j}}+\frac{\partial u_{m i}}{\partial x_{i}}\right)\right] \\
& +\frac{\partial}{\partial x_{j}}\left(-\rho_{m} \overline{u_{m i}^{\prime} u_{m j}^{\prime}}\right) \\
& +\frac{\partial}{\partial x_{j}}\left(\sum_{k=1}^{n} \rho_{k} u_{d r}, k i u_{d r}, k j\right) \\
& +g \rho_{m},
\end{aligned}
$$

where $m$ represents the mixture phases, $n$ is the number of phases, and $-\rho_{m} \overline{u_{m i}^{\prime} u_{m j}^{\prime}}$ is the Reynolds stress term.

It is concluded that the proppant is quartz sand with a particle size of $90 \%$ between $5-30 \mu \mathrm{m}$, viscosity is $1.3 \mathrm{MPa} \cdot \mathrm{s}$, and the density is $1020 \mathrm{~kg} / \mathrm{m}^{3}$ by the analysis of fracturing flow-back fluids. In order to confirm the optimum range of the feed flow rate, a wide range of flow rates from $1 \mathrm{~m} / \mathrm{s}$ to $18 \mathrm{~m} / \mathrm{s}$ are investigated in this work. When the optimum range is confirmed, in each case, the inlet velocity of $6 \mathrm{~m} / \mathrm{s}$ is used at the feed flow rate. The total volume of the liquid and gas is constant, only the GLR is set as a variable while other parameters are kept the same, the range GLR is $0-20 \%$. The structural parameters are shown in Table 1.

A "velocity inlet" boundary condition is used at the inlet, and the "out-flow" condition is used at both overflow and underflow. A "no-slip" boundary condition is set at the wall. "SIMPLE" is set at the pressure-velocity coupling, "QUICK" is set at the discretization scheme of volume fraction and momentum, and "PRESTO!" is used at the discretization scheme of pressure. 
TABle 1: Parameters of hydrocyclone.

\begin{tabular}{lcc}
\hline Parameter & Symbol & Value \\
\hline Diameter of the body & $D$ & $50 \mathrm{~mm}$ \\
Diameter of inlet & $D_{i}$ & $12 \times 8 \mathrm{~mm}^{2}$ \\
Diameter of vortex finder & $D_{\mathrm{o} 1}$ & $15 \mathrm{~mm}$ \\
Diameter of outlet & $D_{\mathrm{o} 2}$ & $8 \mathrm{~mm}$ \\
Length of cylindrical part & $L_{\mathrm{c} 1}$ & $72 \mathrm{~mm}$ \\
Length of cone part & $L_{\mathrm{c} 2}$ & $159.5 \mathrm{~mm}$ \\
Length of vortex finder & $L_{\mathrm{v}}$ & $50 \mathrm{~mm}$ \\
Particle material & $S$ & Quartz sand \\
Mean particle density & $\rho_{\mathrm{p}}$ & $2650 \mathrm{~kg} / \mathrm{m}^{3}$ \\
Feed solids concentration & $\rho_{\mathrm{feed}}$ & $3 \%$ \\
\hline
\end{tabular}

Figure 1 is the structural parameter and meshing of the hydrocyclone. Verifying the mathematical model before numerical simulation can reduce errors of numerical simulation [26]. The RSM model was validated against experimental results measured using PIV. The models with $300,000,350,000,400,000$, and 450,000 meshes were simulated, the axial velocity at $Z=72 \mathrm{~mm}$ was compared, and the axial velocity at $Z=72 \mathrm{~mm}$ was tested by PIV.

As can be seen from Figure 2, when the number of meshes reaches 400,000 the axial velocity is almost unchanged, and the two velocity curves are consistent basically by the PIV experiment and CFD numerical simulation. Based on the above analysis, it can be concluded that the CFD can predict the internal flow field of hydrocyclones.

\section{Results and Discussion}

3.1. Optimum Range of Inlet Velocity. An air core is formed in the negative pressure zone of the hydrocyclone, and the stability of the air core determines the lower limit of inlet velocity of the hydrocyclone (in this study, the air core is defined as the region where the volume fraction of air is greater than 90\%). With an increase in the inlet velocity from $1 \mathrm{~m} / \mathrm{s}$ to $18 \mathrm{~m} / \mathrm{s}$, three representative stages have emerged.

It can be seen from Figure 3(a) that there is an irregular shape of the air core in the internal flow field and there is a tendency to interrupt near the spigot. When the inlet velocity reaches $2 \mathrm{~m} / \mathrm{s}$ (Figure 3(b)), the air core is formed gradually but the fluctuation is large. As the inlet velocity increases (Figure 3(c)), the diameter of the air core does not change with time and forms a regular columnar structure at the axis of the hydrocyclone with a slight oscillation at the bottom of vortex finder. This evolution of the air core is consistent with Cui's experimental study [28].

When the inlet velocity is $2 \mathrm{~m} / \mathrm{s}$ (Figure $4(\mathrm{a})$ ), the diameter of the air core changes with time continuously and presents irregular oscillation in the region of $Z=25 \mathrm{~mm}$ to $Z=200 \mathrm{~mm}$. The air core diameter is stable when the inlet velocity is greater than $4 \mathrm{~m} / \mathrm{s}$ (Figures $4(\mathrm{~b})$ and $4(\mathrm{c})$ ), but there is still a slight change in the bottom of vortex finder. It can be seen from Figure 4(d) that when the inlet velocity is too large $(v>14 \mathrm{~m} / \mathrm{s})$, the variation in the bottom of vortex finder will become larger, and the air core is no longer a stable value. It has been found that a stable air core can be

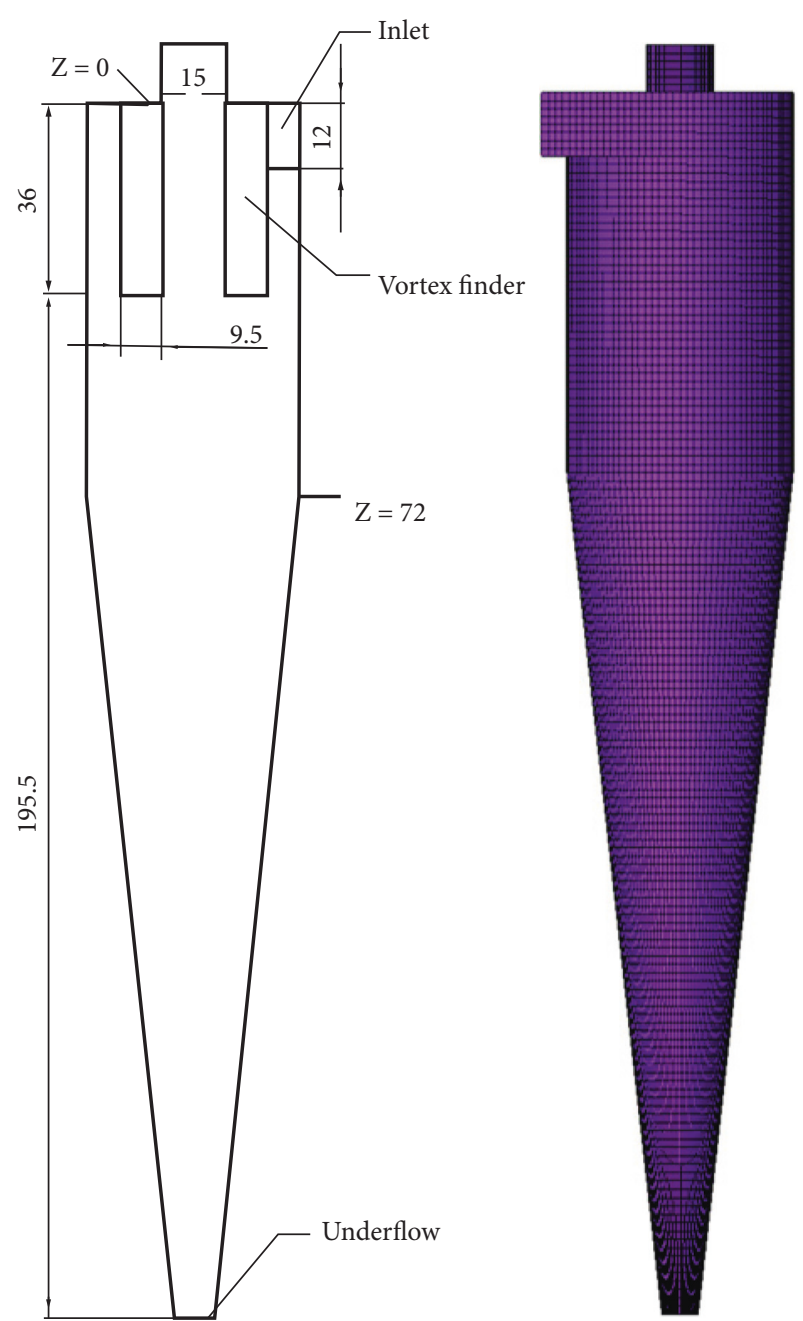

Figure 1: Physical model and meshing.

formed at an inlet velocity of $4 \mathrm{~m} / \mathrm{s}$ to $14 \mathrm{~m} / \mathrm{s}$. In summary, the hydrocyclone has a minimum inlet velocity of $4 \mathrm{~m} / \mathrm{s}$ under this operating condition.

Figure 5shows the characteristic curve of tangential velocity at different inlet velocities of the hydrocyclone at $Z=72 \mathrm{~mm}$ and $Z=36 \mathrm{~mm}$. It can be seen that the tangential velocity increases with the increase of inlet velocity in the area far from the vortex finder, as shown in Figure 5(a). But in the area near the vortex finder, the tangential velocity can be constant or can even decrease with the decrease in the radius, as indicated by the black rectangle of Figure 5(b). Because a higher proportion of pressure energy is wasted, the vortex intensity would stop rising when the inlet velocity is too large, and the vortex finder is the area with the highest turbulence intensity, which is similar to the conclusion obtained by Exall [11]. It can be seen from Figure 5(b) that when the inlet velocity is within $4 \mathrm{~m} / \mathrm{s}-8 \mathrm{~m} / \mathrm{s}$, the tangential velocity remains constant in the free vortex region near the vortex finder. When the inlet velocity is greater than $10 \mathrm{~m} / \mathrm{s}$, the tangential velocity begins to decrease. In order to reduce the energy consumption and turbulence intensity, the highest practicable inlet velocity is $10 \mathrm{~m} / \mathrm{s}$. 


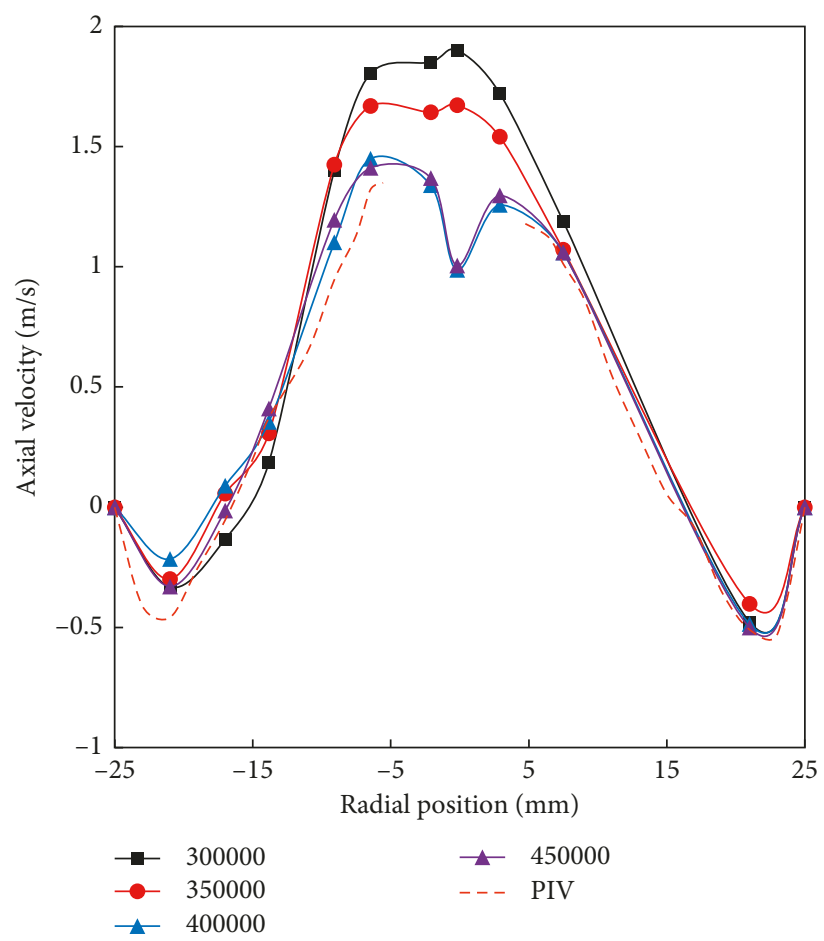

FIGURE 2: Comparison of distributions of axial velocities.

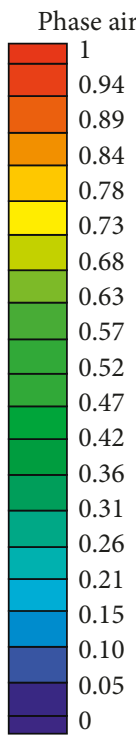

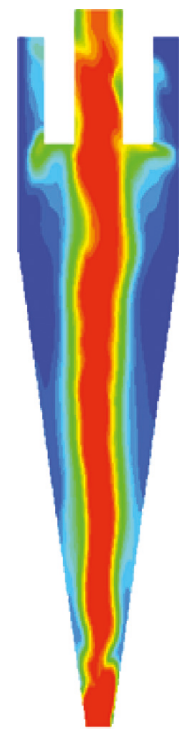

(a)

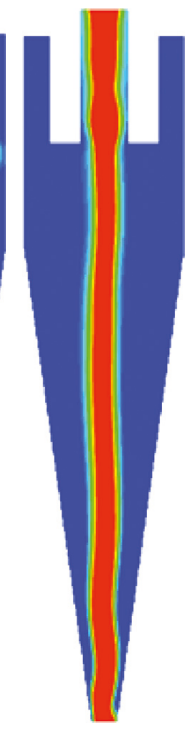

(b)

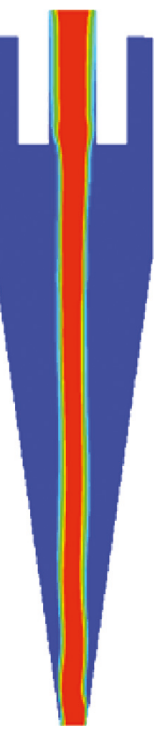

(c)

Figure 3: Patterns of the air core in a hydrocyclone. (a) $V=1 \mathrm{~m} / \mathrm{s}$; (b) $V=2 \mathrm{~m} / \mathrm{s}$; (c) $V=14 \mathrm{~m} / \mathrm{s}$.

\subsection{GLR}

3.2.1. Pressure and Pressure Drop. The internal flow field of the hydrocyclone is a strong swirling flow, which causes certain energy loss. The pressure loss is the premise of the effective separation [26].

Figure 6 shows the characteristic curve of pressure at different inlet velocities of the hydrocyclone. When the GLR (volume fraction) is 0 , the pressure at the wall is the largest, and the maximum value is $84 \mathrm{kPa}$. When the GLR is $20 \%$, the pressure at the wall is the smallest, and the minimum value is $66 \mathrm{kPa}$, but the negative pressure value stabilizes at $-5 \mathrm{kPa}$. As we can seen from Figure 7 that as the GLR increases, the pressure drop of overflow and underflow is decreasing continuously, and the trend of change is linear function. The overflow pressure drop is slightly smaller than the underflow pressure drop, and the reduction of pressure drop can reduce energy consumption. It is against the results of Zhao. 

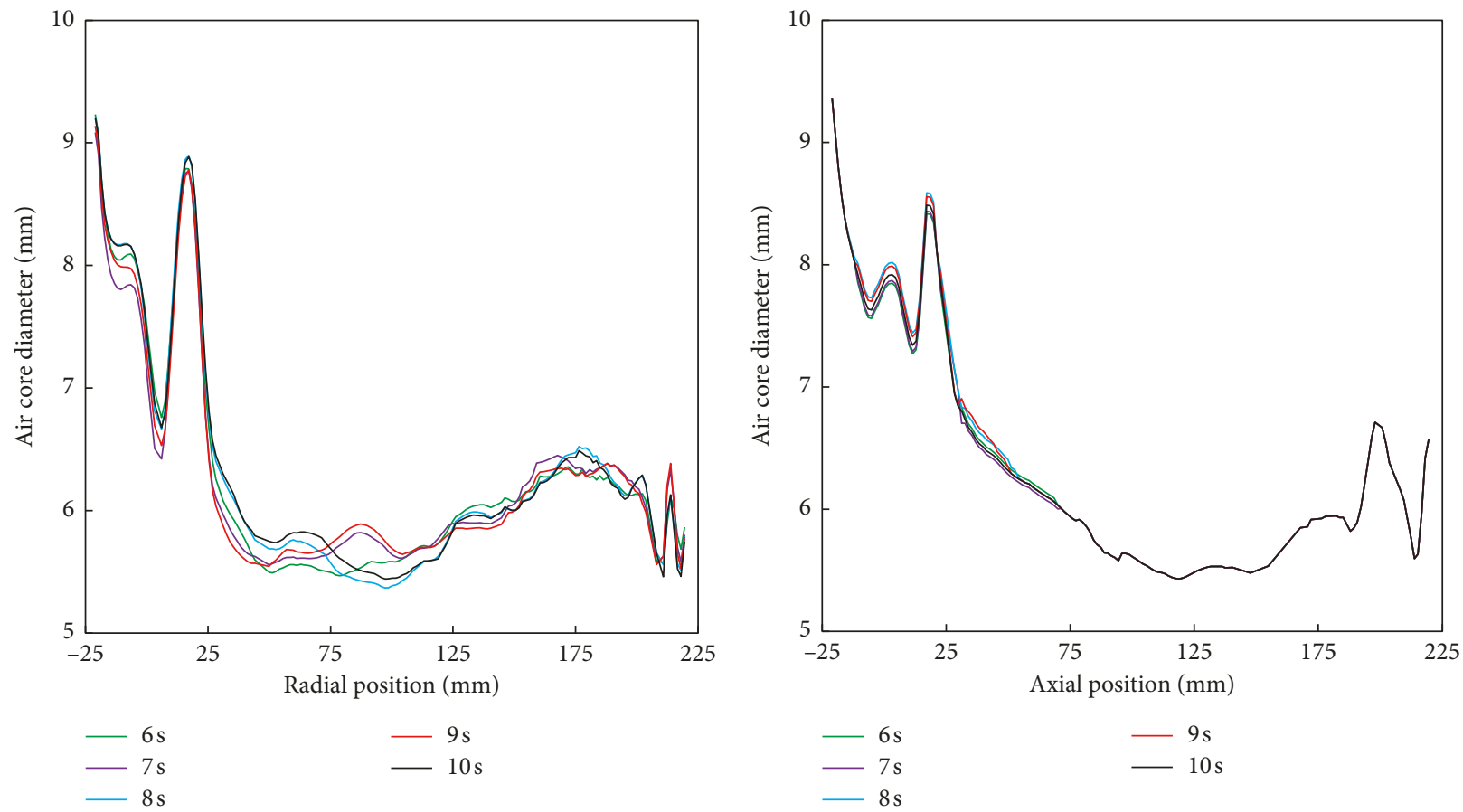

(a)
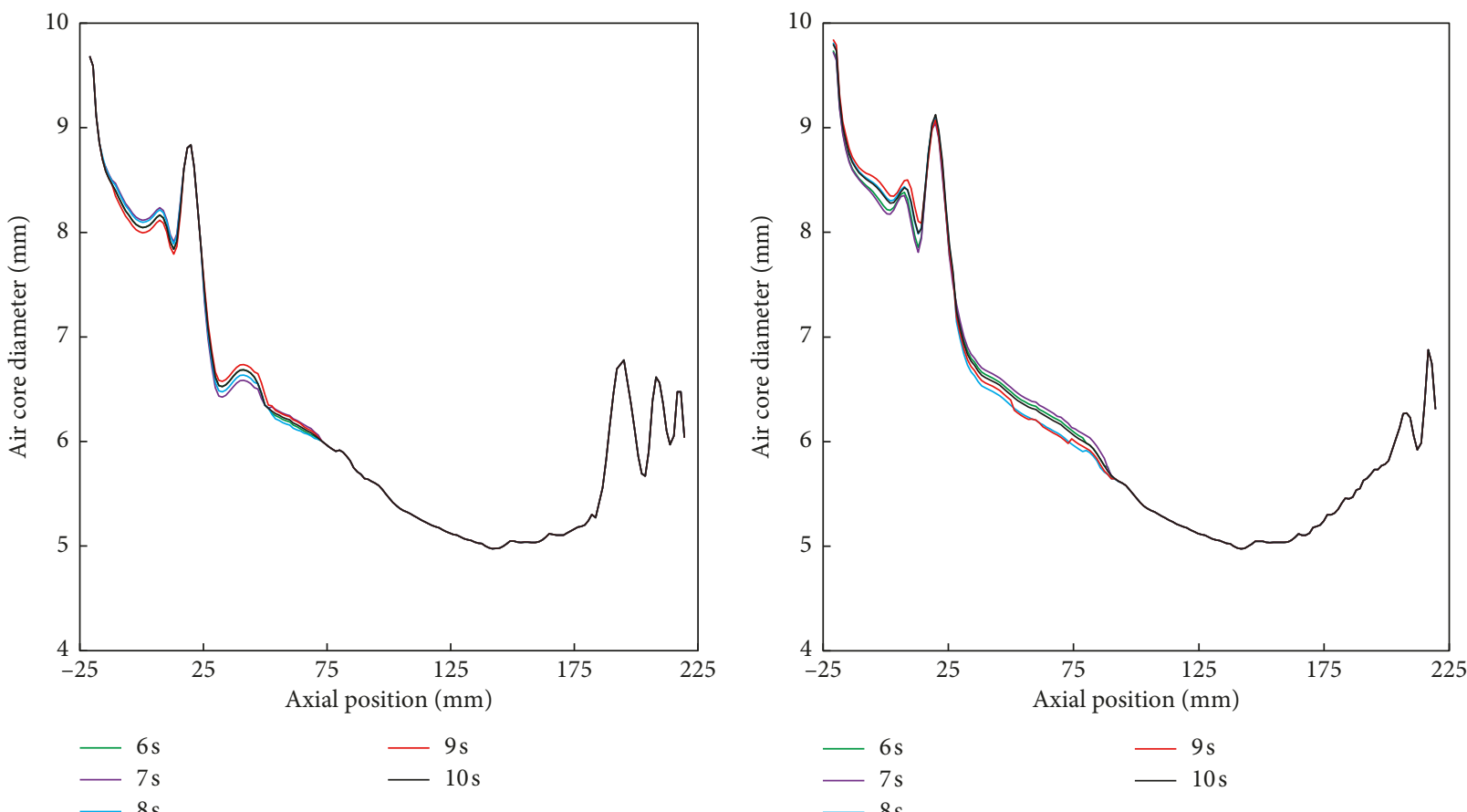

(c)

(d)

Figure 4: Air core diameters at different times with inlet velocity. (a) $V=2 \mathrm{~m} / \mathrm{s}$; (b) $V=4 \mathrm{~m} / \mathrm{s}$; (c) $V=6 \mathrm{~m} / \mathrm{s}$; (d) $V=18 \mathrm{~m} / \mathrm{s}$.

Because Zhao et al. conducted a study of injecting gas with a constant liquid flow rate [19], the inlet velocity was increased and the pressure consumption caused a large pressure drop.

3.2.2. Tangential Velocity. As can be seen from Figure 8(a), at the segment of the column of the hydrocyclone, the peak of tangential velocity increases with the increase of the GLR, and the positions of peak value move inward gradually. The stress region and the effective separation region become larger. As can be seen from Figure 8(b), the position of the cone segment is not significantly affected by the GLR.

As can be seen from Figure 8, the tangential velocity distribution is a Rankine vortex with a quasi-free vortex in 


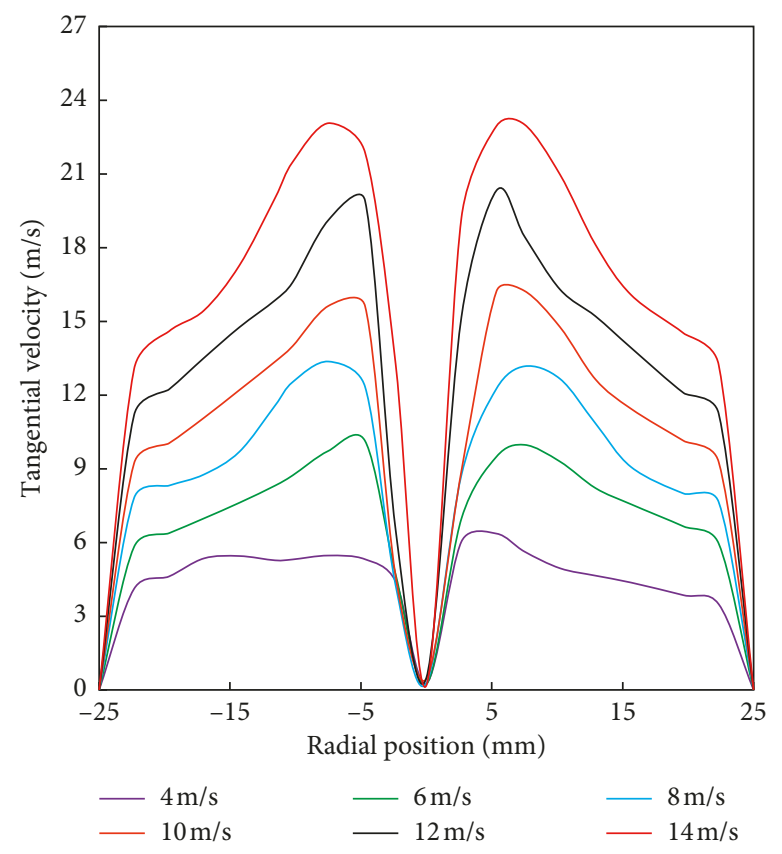

(a)

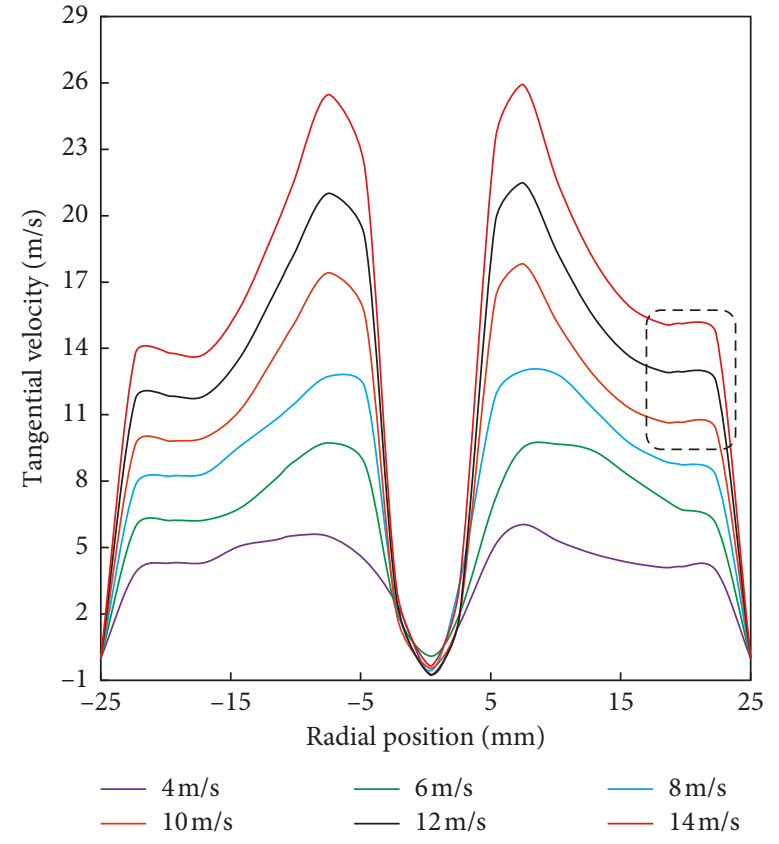

(b)

Figure 5: Characteristic curve of tangential velocity. (a) $Z=72 \mathrm{~mm}$; (b) $Z=36 \mathrm{~mm}$.

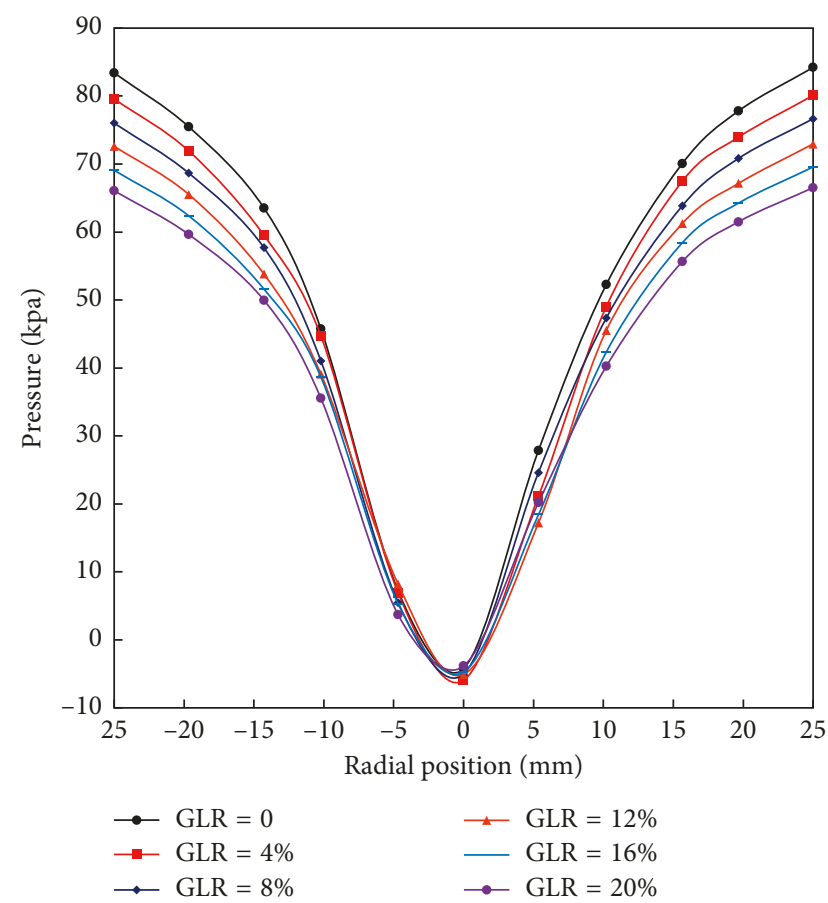

FIGURE 6: Characteristic curve of pressure.

the outer and a quasi-forced vortex in the inner part [29]. According to the Bernoulli equation, the Rankine vortex can be derived. That is,

$$
u_{\mathrm{t}} r^{n}=c,
$$

where $u_{\mathrm{t}}$ is the tangential velocity of the fluid particle in the flow field, $r$ is the radius of rotation of the fluid particle, $C$ is a constant, and $n$ is an index.

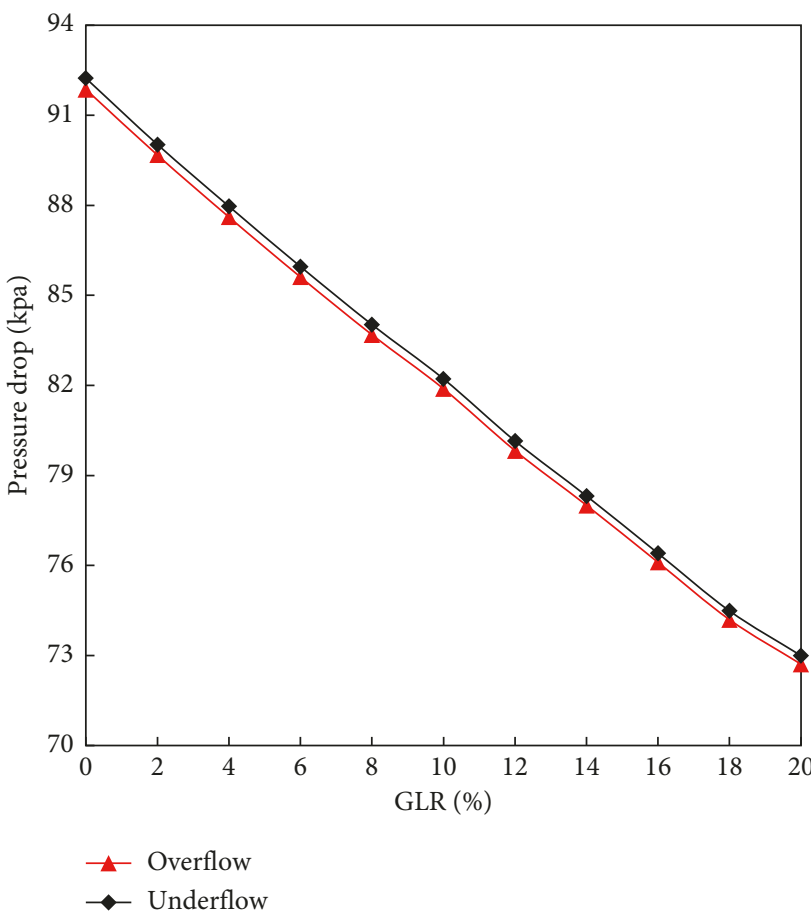

FIgURE 7: Characteristic curve of pressure drop.

In separation duties, tangential velocity with a large rate of change is beneficial for the separation of particles, because tangential velocity with a large rate of change produce high shearing stress. To some extent, the $n$ value can reflect the change rate of tangential velocity. According to formula (3), taking the tangential velocity value of the internal flow field between two adjacent points and approximating that the 


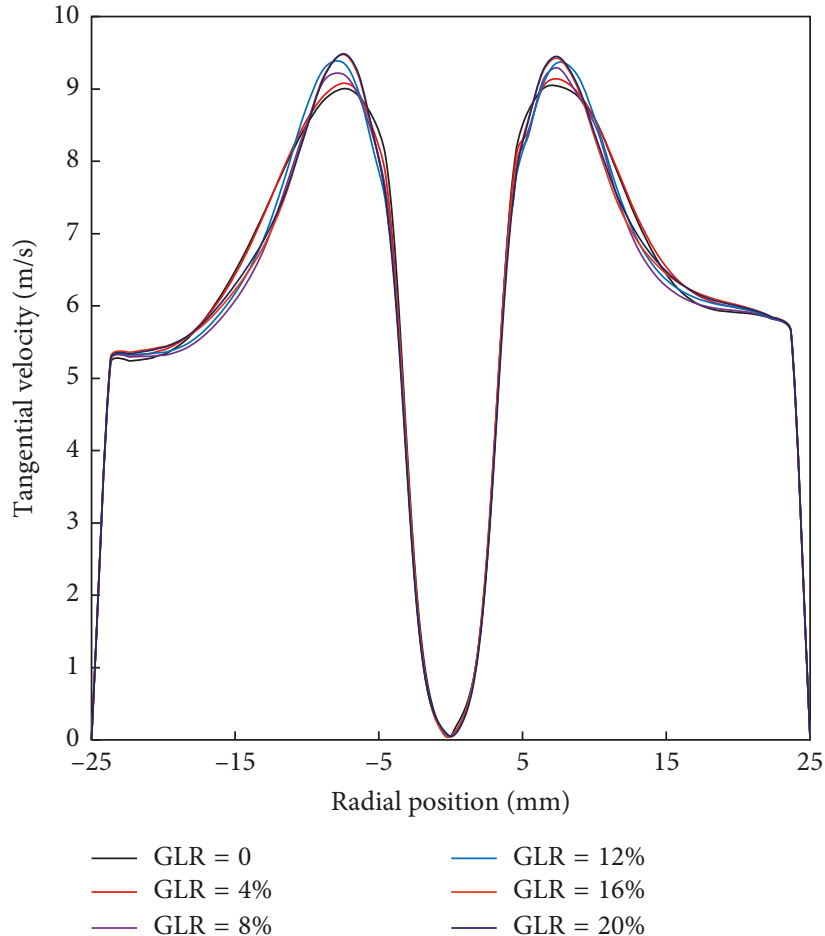

(a)

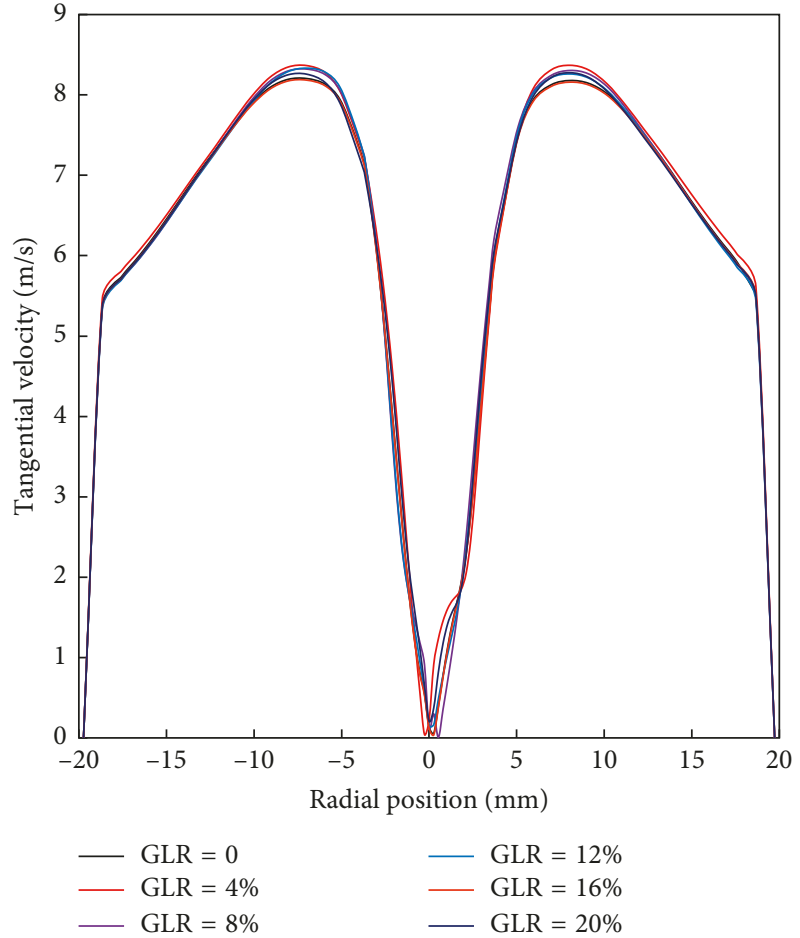

(b)

FIGURE 8: Characteristic curve of tangential velocity. (a) $Z=36 \mathrm{~mm}$; (b) $Z=100 \mathrm{~mm}$.

motion between the adjacent two detection points conforms to formula (3) [30], that is, $u_{\mathrm{t}(i)} r_{i}^{n}=u_{\mathrm{t}(i+1)} r_{i+1}^{n}$, it is inferred that

$$
n_{i-i+1}=\frac{\ln u_{\mathrm{t}(i)}-\ln u_{\mathrm{t}(i+1)}}{\ln r_{i+1}-\ln r_{i}}
$$

where $r_{i}$ is the radius of rotation at the monitoring point, $u_{\mathrm{t}(i)}$ is the tangential velocity at the monitoring point, and $n_{i-i+1}$ is the value of $n$ at the two detection points.

Since the cone section is not affected by the GLR significantly and the column section is the main separation segment, the value of $n$ is analyzed in the column section.

It can be seen from Table 2 . The value of $n$ increases while the GLR increases. The value of $n$ near the vortex finder is lower than the value of $n$ near the cone, and the average is reduced by 0.014 because in the internal flow field of the hydrocyclone the maximum turbulence intensity appears at the vortex finder, which causing the tangential velocity to stop increasing or even decreasing.

3.2.3. Axial Velocity. Figure 9 compares the axial velocities with different GLRs. From the wall to the center, the direction of axial velocity is opposite; that is, the outside is downward and the inside is upward, and this phenomenon of the axial velocity is consistent with Marins's experimental study by LDV [31], as can be seen from Figures 9 and 10 that the axial velocity of the column section and the cone section are reduced with the increase of GLR. In the column section (Figure 9(a)), the maximum axial velocity appears in the area
TABle 2: $n$ value.

\begin{tabular}{lccccccc}
\hline$n$ value & GLR (\%) & 0 & 4 & 8 & 12 & 16 & 20 \\
\hline Section & & & & & & & \\
$Z=36$ & 0.866 & 0.867 & 0.870 & 0.880 & 0.881 & 0.883 \\
$Z=72$ & 0.881 & 0.883 & 0.886 & 0.893 & 0.895 & 0.897 \\
\hline
\end{tabular}

near the air core and the maximum value is $3.35 \mathrm{~m} / \mathrm{s}$. The minimum axial velocity appears in the area near the wall, and the minimum value is $-1.85 \mathrm{~m} / \mathrm{s}$. It can be seen from Figure $9(\mathrm{~b})$ that the maximum positive axial velocity is $1.05 \mathrm{~m} / \mathrm{s}$ when the GLR is 0 , and the minimum positive axial velocity is $0.93 \mathrm{~m} / \mathrm{s}$ when the GLR is $20 \%$. But there is a slight change in the negative axial velocity. The reduction in the axial velocity causes more mixture to drain to the spigot.

The area where the black line is located in Figure 11 is the locus of zero vertical velocity (LZVV). It can be seen from the Figure 11 that as the GLR increases, the LZVV shifts to the inside gradually, and in the column section area, the trend is even more pronounced. It can be seen from Figure 9(a) that as the GLR increases, the intersection of the axial velocity and the $x=0$ line are closer to the air core. To some extent, this phenomenon will reduce the split ratio [27] (here, the split ratio is defined as the ratio of the vortex finder to the inlet), and it can reduce the short-circuit flow and improve the separation efficiency of particles.

3.2.4. Radial Stress of Particles. The stress of the particles in the radial direction is mainly centrifugal stress $F_{c}[32,33]$, centripetal buoyancy $F_{\mathrm{b}}$, and fluid resistance $F_{\mathrm{s}}$. The radial 


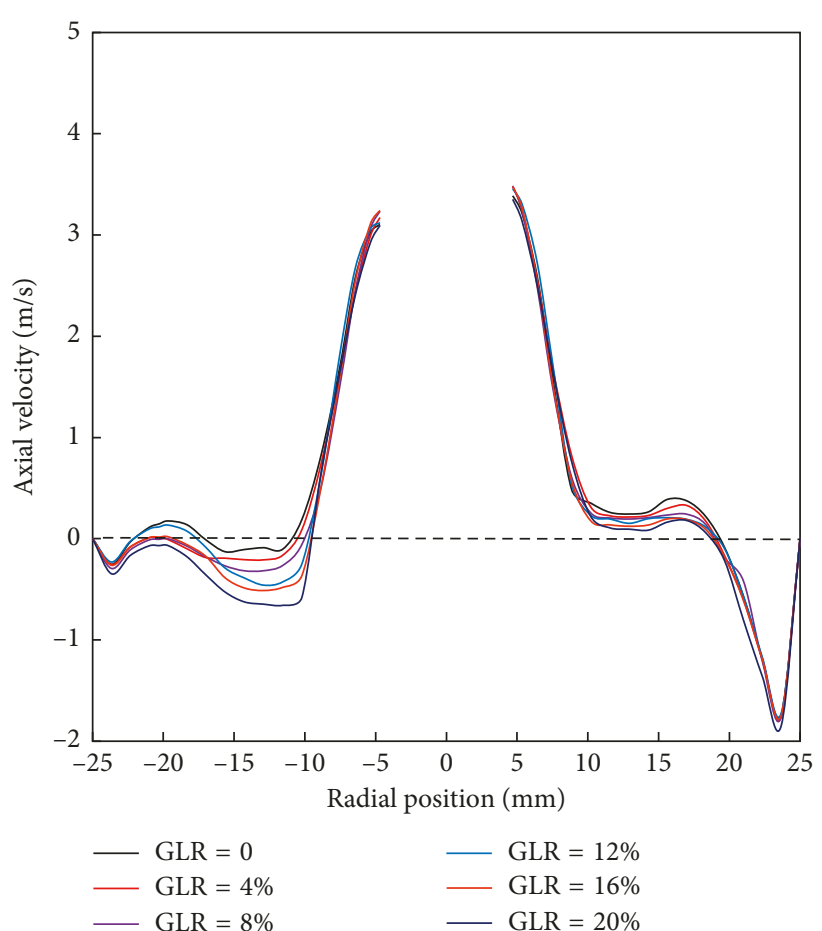

(a)

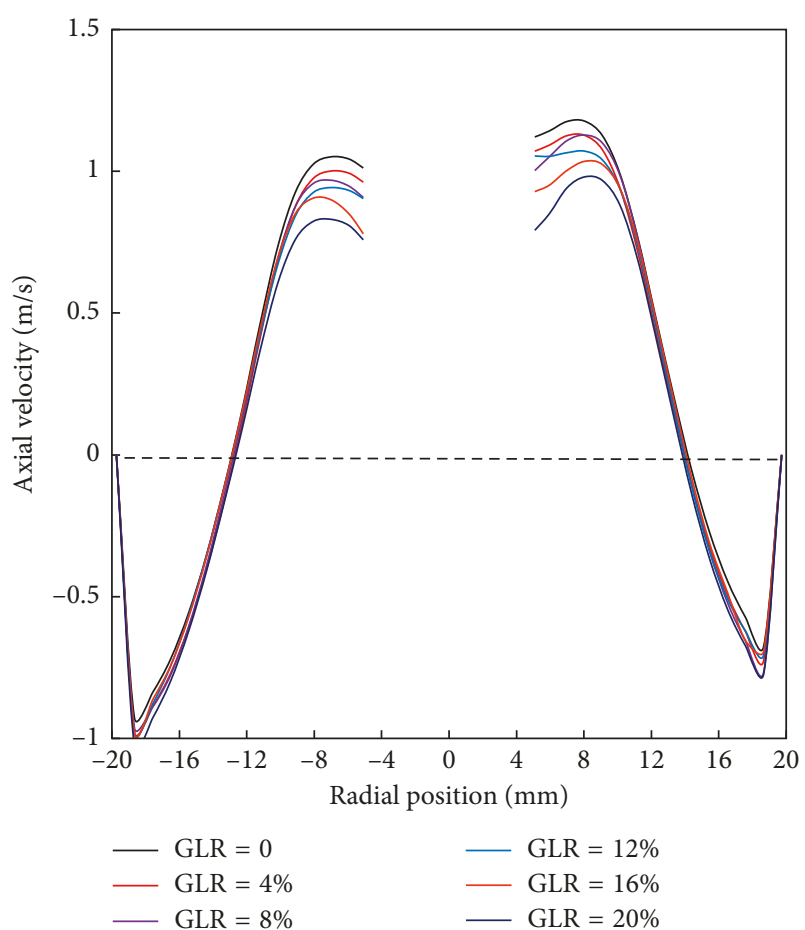

(b)

Figure 9: Characteristic curve of axial velocity. (a) $Z=36 \mathrm{~mm}$; (b) $Z=100 \mathrm{~mm}$.
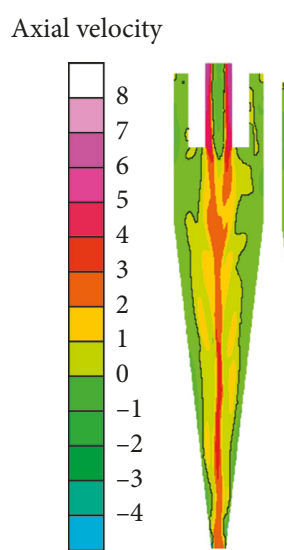

(a)

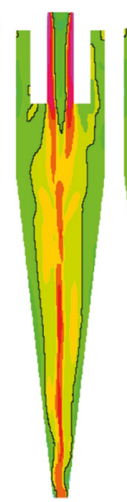

(b)

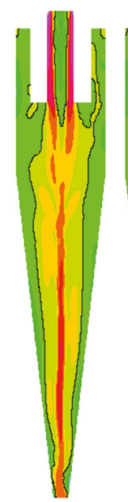

(c)

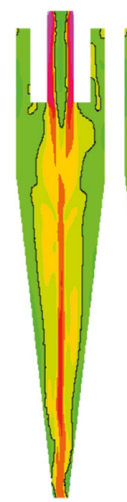

(d)

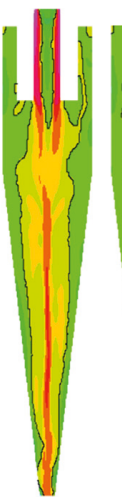

(e)

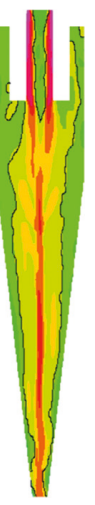

(f)

Figure 10: LZVV and axial velocity. (a) GLR=0; (b) GLR = 4\%; (c) GLR $=8 \%$; (d) GLR $=12 \%$; (e) GLR=16\%; (f) GLR $=20 \%$.

stress of the particles inside the hydrocyclone is shown in Figure 11; that is,

$$
\begin{aligned}
& F_{\mathrm{b}}=\frac{\pi}{6} d^{3} \rho g, \\
& F_{\mathrm{c}}=\frac{\pi}{6} d^{3} \rho_{d} \frac{u_{\theta}^{2}}{r}, \\
& F_{\mathrm{s}}=3 \pi \mu d u_{0},
\end{aligned}
$$

where $d$ is the diameter of particles, $\rho$ is the density of the continuous phase, $\rho_{d}$ is the density of particles, $g$ is the

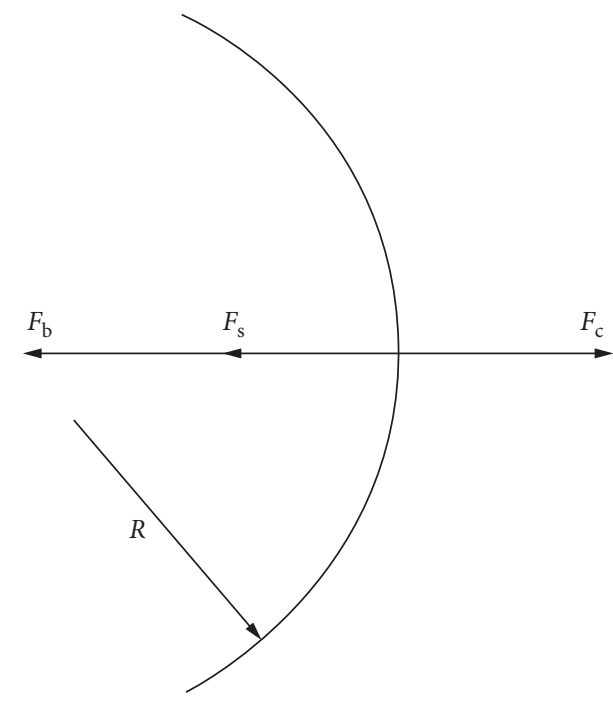

Figure 11: Radial stress of particles inside hydrocyclone.

gravitational acceleration, and $u_{0}$ is the velocity difference between the particles and the fluid.

Therefore, the stress equation of the particle is

$$
F=\frac{\pi}{6} d^{3}\left(\rho_{d}-\rho\right) \frac{u_{\theta}^{2}}{r}-3 \pi \mu d u_{0} .
$$

It can be seen from Figures 12 and 13 that the viscosity $\mu$ and density $\rho$ of the continuous phase decreases as the GLR increases, which is caused by the distribution of the gas phase in the internal flow field. The density $\rho_{d}$ of the solid 


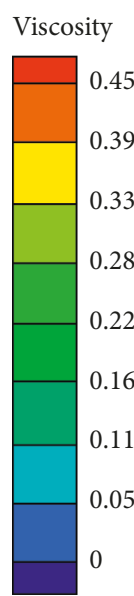

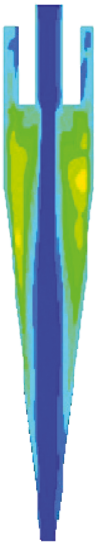

(a)

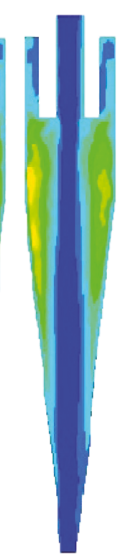

(b)

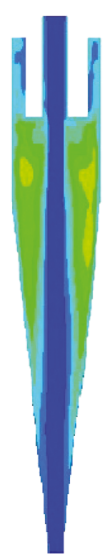

(c)

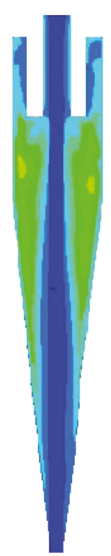

(d)

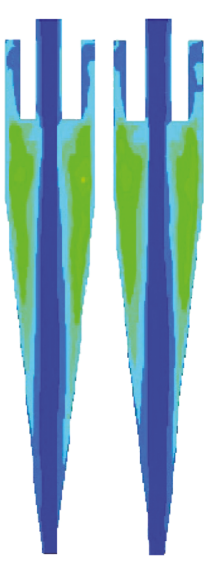

(e) (f)

Figure 12: Viscosity of continuous phase. (a) $\mathrm{GLR}=0$; (b) $\operatorname{GLR}=4 \%$; (c) GLR $=8 \%$; (d) GLR $=12 \%$; (e) $\mathrm{GLR}=16 \%$; (f) $\mathrm{GLR}=20 \%$.

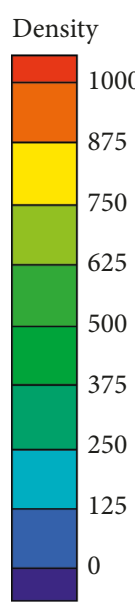

(a)

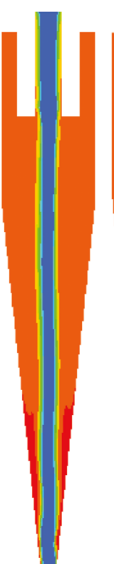

(b)

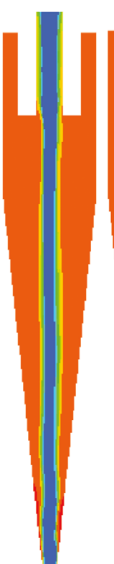

(c)

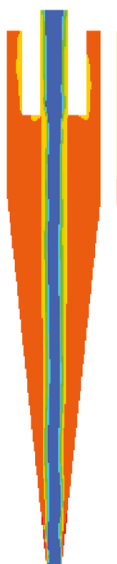

(d)

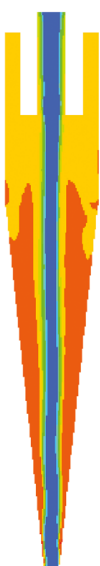

(e)

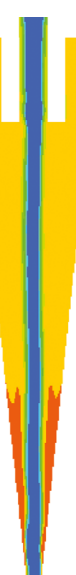

(f)

FIGURE 13: Density of continuous phase. (a) $G L R=0$; (b) $\mathrm{GLR}=4 \%$; (c) GLR $=8 \%$; (d) GLR $=12 \%$; (e) $\mathrm{GLR}=16 \%$; (f) $\mathrm{GLR}=20 \%$.

particles does not change with the increase of GLR, and the $u_{\theta}^{2} / r$ increases with the increase of GLR. The velocity difference $u_{0}$ is tiny and can be ignored. Therefore, by formula (6), the radial stress of the particles in the inner flow field can be increased, which will be more favorable for the movement of the particles in the radial direction.

\section{Experimental Setup and Results}

In order to approach the treatment environment of fracturing flow-back fluids, the temperature is set to $25^{\circ} \mathrm{C}$ and the viscosity of the liquid is $1.3 \mathrm{mPas}$. The density of quartz sand is $2650 \mathrm{~kg} / \mathrm{m}^{3}$. The volume fraction of particles is $3 \%$. The GLR is controlled by adjusting the valves 7 and 9 during the experiment. The experimental setup is shown in Figure 14.

Figure 15 shows the split ratio at different GLRs. It can be seen that the split ratio $\left(R_{\mathrm{f}}\right)$ is $87.09 \%$ when the GLR is 0 ,

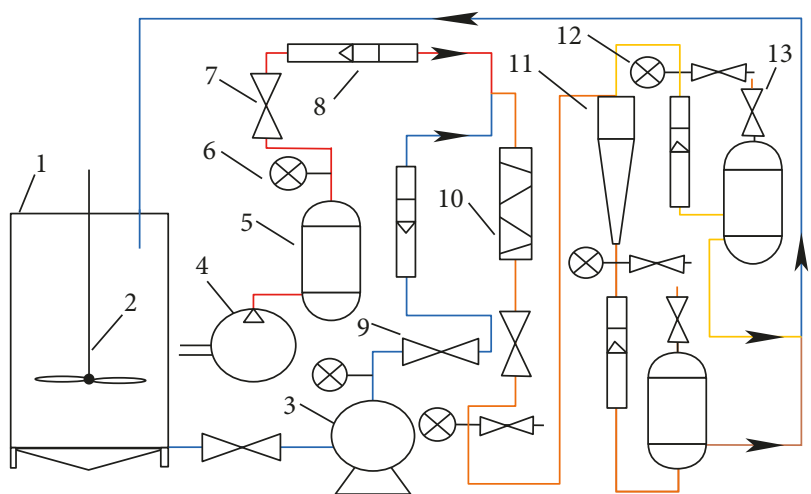

FIgURE 14: Experimental setup. (1) Stirring tank; (2) agitator; (3) pump; (4) air compressor; (5) buffer tank; (6) pressure gauge; (7) valve; (8) flow meter; (9) valve; (10) static mixer; (11) hydrocyclone; (12) sampling port; (13) venting.

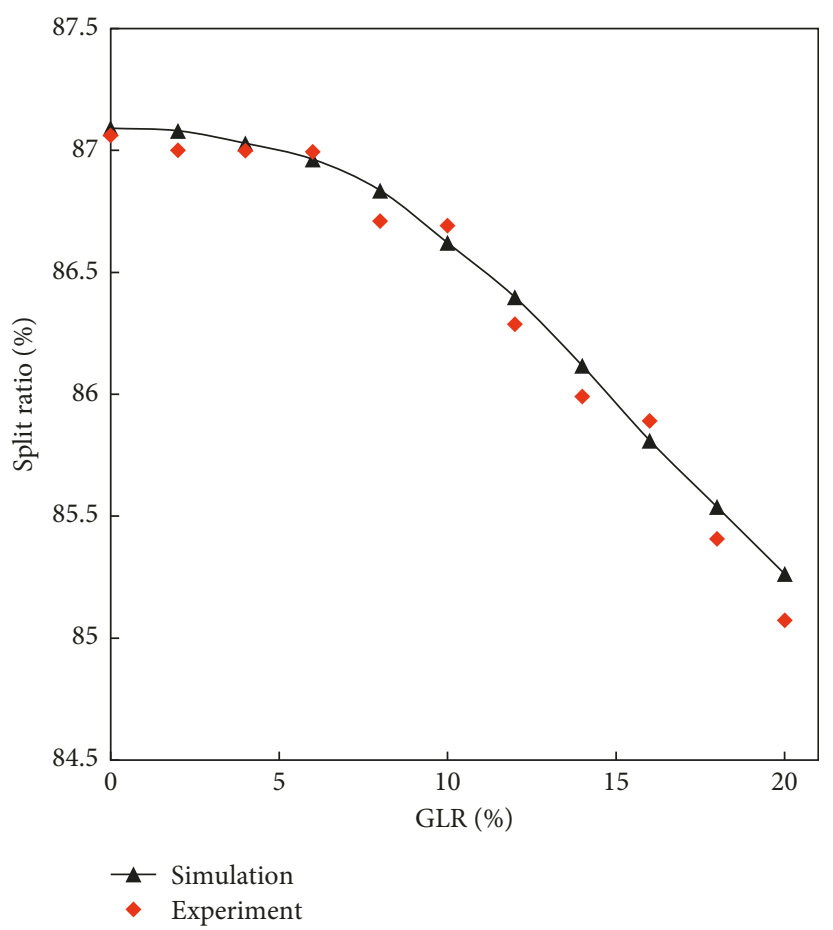

FIgURE 15: Characteristic curve of split ratio.

and the minimum split ratio is $85.26 \%$ when the GLR is $20 \%$, then the split ratio decreases with the increase in GLR. The split ratio is decreased by $0.51 \%$ when GLR $=0$ to GLR $=2 \%$, but the split ratio is decreased by $13.68 \%$ when GLR $=18 \%$ to GLR $=20 \%$.

Because of the density, the gas is separated first and concentrated at the vortex finder, which hinder the liquid and particles entering the vortex finder. In addition, as can be seen from Figure 9(a), as the GLR increases, the negative axial velocity increases, and this phenomenon causes more mixture to drain to the spigot; as the GLR increases, the LZVV shifts to the inside gradually (Figure 10), which reduces the short-circuit flow. Thus, the split ratio decreases as the GLR increases. 


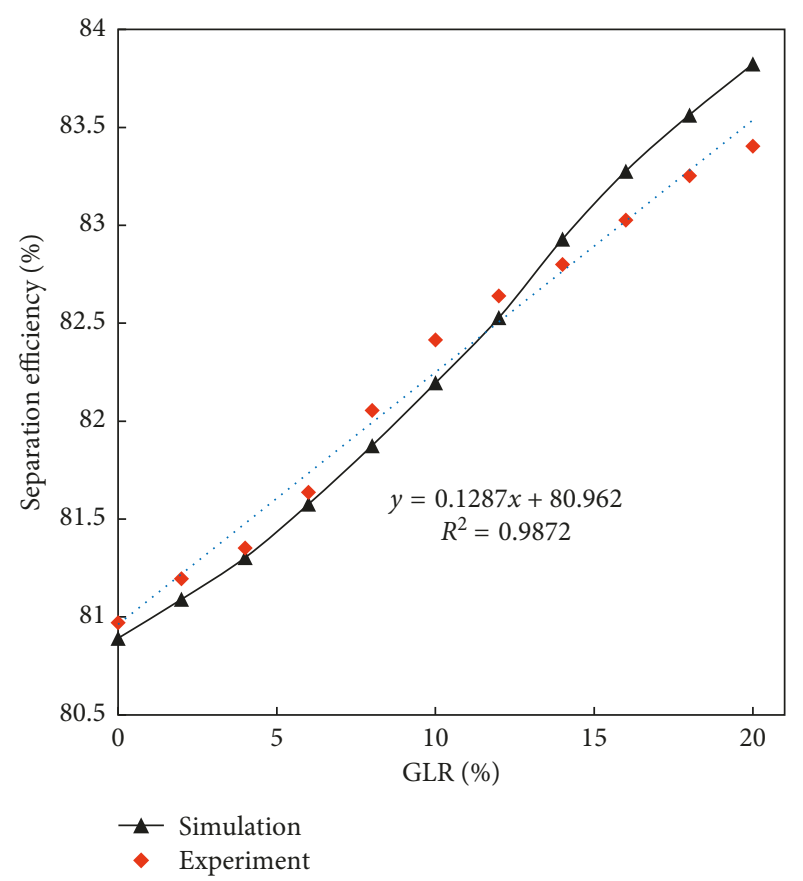

FIgURE 16: Characteristic curve of separation efficiency.

Figure 16 is the characteristic curve of separation efficiency. The separation efficiency of solid particles is $80.97 \%$ when the GLR is 0 and $83.40 \%$ when the GLR is $20 \%$. The higher the GLR is, the higher the separation efficiency is, and the distribution of the separation efficiency is a linear function. The fitness formula is $y=0.1287 x+80.962$ (where $y$ is the separation efficiency and $x$ is the GLR) and $R^{2}=0.9872$.

It can be seen from Figure 17 that the particle size of $15 \mu \mathrm{m}$ is affected greatly by the GLR, and the separation efficiency is increased by $6.75 \%$. The particle size of $30 \mu \mathrm{m}$ is affected less by the GLR, and the separation efficiency is increased by $0.57 \%$. When the particle size is between $5 \mu \mathrm{m}$ and $20 \mu \mathrm{m}$, the separation efficiency increases with the increase of the particle diameter. When the particle diameter is larger than $20 \mu \mathrm{m}$, the degree of separation efficiency does not change significantly with the increase of the particle diameter. In addition, as the GLR increases, the cut size $\left(\mathrm{d}_{50}\right)$ shifts to the left; that is, the cut size is reduced with the increase of GLR.

The reasons for this phenomenon can be concluded as follows: the tangential velocity determines the magnitude of centrifugal force and the $n$ value can reflect the steepness of the tangential velocity inside the vortex region. With the increase of tangential velocity and $n$ value, the radial stress of particles becomes larger. In addition, with the decrease of viscosity and density of continuous phase the radial stress of the particles in the internal flow field can be increased, which will be more favorable for the movement of the particles in the radial direction.

\section{Conclusion}

Based on the Reynolds stress model (RSM) of the computational fluid dynamics (CFD) software Fluent and

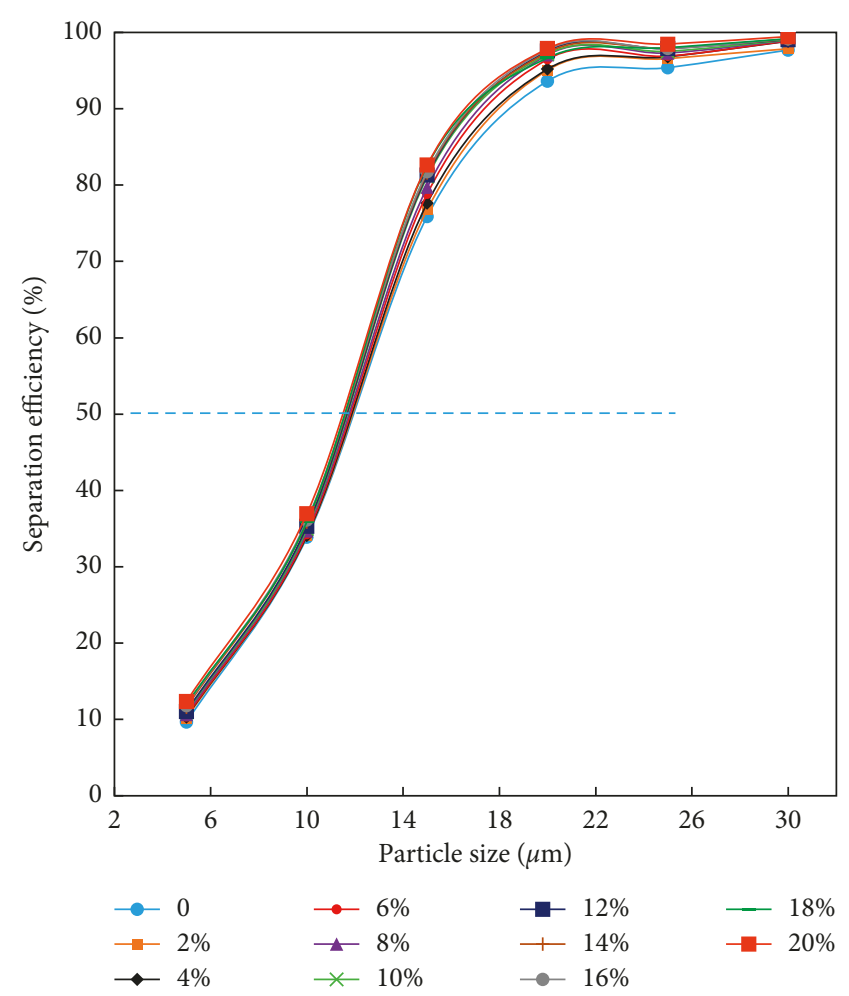

FIGURE 17: Characteristic curve of separation efficiency.

experimental method, the internal flow field and external characteristics under different GLRs and the optimum range of inlet velocity are studied. The major findings from the present study can be summarized as follows:

(1) The optimum range of inlet velocity for fracturing fluids is determined by analyzing the internal flow field; that is, the lower limit is ascertained by the flow field stability, and the lower limit is $4 \mathrm{~m} / \mathrm{s}$. The upper limit is largely determined by the energy consumption, and the upper limit is $10 \mathrm{~m} / \mathrm{s}$.

(2) Within the optimum range, the pressure decreases while the GLR increases; that is, when the GLR is 0, the pressure at the wall is the largest, and the maximum value is $84 \mathrm{kPa}$. When the GLR is $20 \%$, the pressure at the wall is the smallest, and the minimum value is $66 \mathrm{kPa}$. The pressure drop of overflow and underflow are decreasing continuously, and the trend of change is linear function. The overflow pressure drop is slightly smaller than the underflow pressure drop, and the average difference is $0.33 \mathrm{kPa}$.

(3) The peak of tangential velocity increases with the increase of the GLR, and the positions of peak value move inward gradually. The forced region becomes larger, and the effective separation region becomes larger, but the position of the cone segment is not affected by the GLR significantly. With increasing GLR, the value of exponent $n$ for the tangential velocity inside free vortex region is increased, leading to a slight increase of separation performance for particles. 
(4) The axial velocity of the column section and the cone section are reduced with the increase of GLR. The LZVV shifts to the inside gradually, and in the column section area, the trend is even more pronounced. The increase in the GLR causes more gas to collect at the vortex finder, which hinders the discharge of the solid-liquid mixture from the vortex finder. The larger the GLR, the faster the decrease in the split ratio; the split ratio is decreased by $0.51 \%$ when $\mathrm{GLR}=0$ to $\mathrm{GLR}=2 \%$, but the split ratio is decreased by $13.68 \%$ when $\mathrm{GLR}=18.8 \%$ to $\mathrm{GLR}=20 \%$.

(5) The particle size of $15 \mu \mathrm{m}$ is affected greatly by the GLR, and the separation efficiency is increased by $6.75 \%$, and then the particle size of $30 \mu \mathrm{m}$ is affected less by the GLR, and the separation efficiency is increased by $0.57 \%$. The higher the GLR is, the higher the separation efficiency is; the distribution of the separation efficiency is a linear function, and the cut size $\left(d_{50}\right)$ is reduced with the increase of GLR.

\section{Data Availability}

The data used to support the findings of this study are available from the corresponding author upon request.

\section{Conflicts of Interest}

The authors declare that they have no conflicts of interest.

\section{Acknowledgments}

This study was financially supported by the Scientific Research Fund Project of National Natural Science Foundation of China (Grant No. 51408347) and the China National Coal Association Science and Technology Research Guidance Project (MTKJ2016-279).

\section{References}

[1] G. Eugenia, A. M. Ionela, and A. C. Tiberiu, "The economic, social and environmental impact of shale gas exploitation in Romania: a cost-benefit analysis," Renewable and Sustainable Energy Reviews, vol. 93, pp. 691-700, 2018.

[2] D. Zhang and T. Yang, "Environmental impacts of hydraulic fracturing in shale gas development in the United States," Petroleum Exploration and Development, vol. 42, no. 6, pp. 876-883, 2015.

[3] F. Liu, B. Wang, D. Pan et al., "Surface flow-back test technology of shale gas in Sichuan basin," Journal of Henan Polytechnic University, vol. 6, pp. 32-34, 2013.

[4] F. Liu, D. Pan, and Y. Qin, "Recovery and treatment technology of fracturing fluid flow-back in shale gas," Drilling \& Production Technology, vol. 38, pp. 69-72, 2015.

[5] H. Wang, Y. Zhang, J. Wang, and H. Liu, "Cyclonic separation technology: researches and developments," Chinese Journal of Chemical Engineering, vol. 20, no. 2, pp. 212-219, 2012.

[6] S.-A. Marthinussen, Y.-F. Chang, B. Balakin, and A. C. Hoffmann, "Removal of particles from highly viscous liquids with hydrocyclones," Chemical Engineering Science, vol. 108, no. 17, pp. 169-175, 2014.
[7] I. Ik-Tae, G. G. Dong, K. S. Min, and Y. K. Park, "A numerical study of the flow characteristics and separation efficiency of a hydrocyclone using the eulerian-eulerian model," KSCE Journal of Civil Engineering, vol. 22, no. 11, pp. 4272-4281, 2018.

[8] W. Kraipech, W. Chen, T. Dyakowski, and A. Nowakowski, "The performance of the empirical models on industrial hydrocyclone design," International Journal of Mineral Processing, vol. 80, no. 2-4, pp. 100-115, 2006.

[9] D. F. Kelsall, "A further study of the hydraulic cyclone," Chemical Engineering Science, vol. 2, no. 6, pp. 254-272, 1953.

[10] L. Yin, C. Qing, C. Yang et al., "Research progress on treatment of fracturing waste fluid," Petrochemical Industry Application, vol. 32, pp. 5-9, 2013.

[11] L. Svarovsky, Hydrocyclones, Holt Rinehart \& Winston, London, UK, 1984.

[12] K. Rietema, "Performance and design of hydrocyclones-II," Chemical Engineering Science, vol. 15, no. 3-4, pp. 303-309, 1961.

[13] S. M. Mousavian and A. F. Najafi, "Influence of geometry on separation efficiency in a hydrocyclone," Archive of Applied Mechanics, vol. 79, no. 11, pp. 1033-1050, 2009.

[14] K. Wu, G. Liu, and Y. Mo, "Theoretical and experimental study on the separation efficiency of a radial jet cyclone," Powder Technology, vol. 295, pp. 1-6, 2016.

[15] C. Zhang, B. Cui, D. Wei, Q. Zhao, N. Luo, and Y. Feng, "Predicting the optimum range of feed flow rate in a hydrocyclone using the method combined flow pattern and equation model," Powder Technology, vol. 319, pp. 279-288, 2017.

[16] L. Y. Chu, Q. Luo, R. H. Yu et al., "Force and movement of particles in an air-injected hydrocyclone," Chemical Equipment Technology, vol. 5, pp. 5-7, 1995.

[17] L. Y. Chu., Q. Luo, R. H. Yu et al., "Study on the flow field in air-sparged hydrocyclone," Industrial Minerals \& Processing, vol. 3, pp. 20-23, 1994.

[18] L. X. Zhao, M. H. Jiang, and A. Belaidi, "Pressure characteristics study of hydrocyclone with free gas injection," China Petroleum Machinery, vol. 32, pp. 1-4, 2004.

[19] L. X. Zhao, B. J. Zhu, F. Li et al., "Influent factors study on the separation performance of the air-injected liquid-liquid hydrocyclones," Chemical Engineering, vol. 35, pp. 43-47, 2007.

[20] M. H. Jiang, L. Han, L. X. Zhao et al., "Study on separation performance of cone-typed three-phase cyclone separator," Chemical Engineering \& Machinery, vol. 38, pp. 434-439, 2011.

[21] S. Gopalakrishnan, Y. Ye, J. D. Miller et al., "Dimensionless analysis of process variables in air-sparged hydrocyclone (ASH) flotation of fine coal," Coal Preparation, vol. 9, no. 3-4, pp. 169-184, 1991.

[22] M. Nonaka and T. Uchio, "Pressure flotation in hydrocyclone," in Proceedings of 2nd International Conference on Hydrocyclones, pp. 381-392, Bath, England, September 1984.

[23] Y. Hao and L. Tan, "Symmetrical and unsymmetrical tip clearances on cavitation performance and radial force of a mixed flow pump as turbine at pump mode," Renewable Energy, vol. 127, pp. 368-376, 2018.

[24] L. Tan, B. Zhu, Y. Wang, S. Cao, and K. Liang, "Turbulent flow simulation using large eddy simulation combined with characteristic-based split scheme," Computers \& Fluids, vol. 94, pp. 161-172, 2014.

[25] M. Narasimha, M. Brennan, and P. N. Holtham, “A review of CFD modelling for performance predictions of 
hydrocyclone," Engineering Applications of Computational Fluid Mechanics, vol. 1, no. 2, pp. 109-125, 2007.

[26] S. B. Kuang, K. W. Chu, A. B. Yu, and A. Vince, "Numerical study of liquid-gas-solid flow in classifying hydrocyclones: effect of feed solids concentration," Minerals Engineering, vol. 31, no. 31, pp. 17-31, 2012.

[27] Z. Qi, S. B. Kuang, and A. B. Yu, "Numerical investigation of the separation behaviours of fine particles in large dense medium cyclones," International Journal of Mineral Processing, vol. 142, pp. 35-45, 2015.

[28] B.-Y. Cui, D.-Z. Wei, S.-L. Gao, W.-G. Liu, and Y.-Q. Feng, "Numerical and experimental studies of flow field in hydrocyclone with air core," Transactions of Nonferrous Metals Society of China, vol. 24, no. 8, pp. 2642-2649, 2014.

[29] B. Cui, C. Zhang, D. Wei, S. Lu, and Y. Feng, "Effects of feed size distribution on separation performance of hydrocyclones with different vortex finder diameters," Powder Technology, vol. 322, pp. 114-123, 2017.

[30] L. C. Ren and M. Jiang, "Effect of medium viscosity on the movement index of combined vortex in a hydrocyclone," Oil Field Equipment, vol. 42, no. 12, pp. 1-6, 2013.

[31] L. P. M. Marins, D. G. Duarte, J. B. R. Loureiro, C. A. C. Moraes, and A. P. S. Freire, "LDA and PIV characterization of the flow in a hydrocyclone without an aircore," Journal of Petroleum Science \& Engineering, vol. 70, no. 3-4, pp. 168-176, 2010.

[32] K. W. Chu, B. Wang, A. B. Yu, and A. Vince, "Particle scale modelling of the multiphase flow in a dense medium cyclone: effect of vortex finder outlet pressure," Minerals Engineering, vol. 31, pp. 46-58, 2012.

[33] K. W. Chu, S. B. Kuang, A. B. Yu, and A. Vince, "Particle scale modelling of the multiphase flow in a dense medium cyclone: effect of fluctuation of solids flowrate," Minerals Engineering, vol. 33, no. 33, pp. 34-45, 2012. 


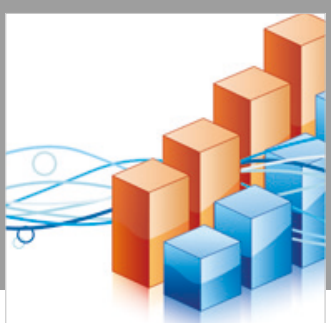

Advances in

Operations Research

\section{-n-m}
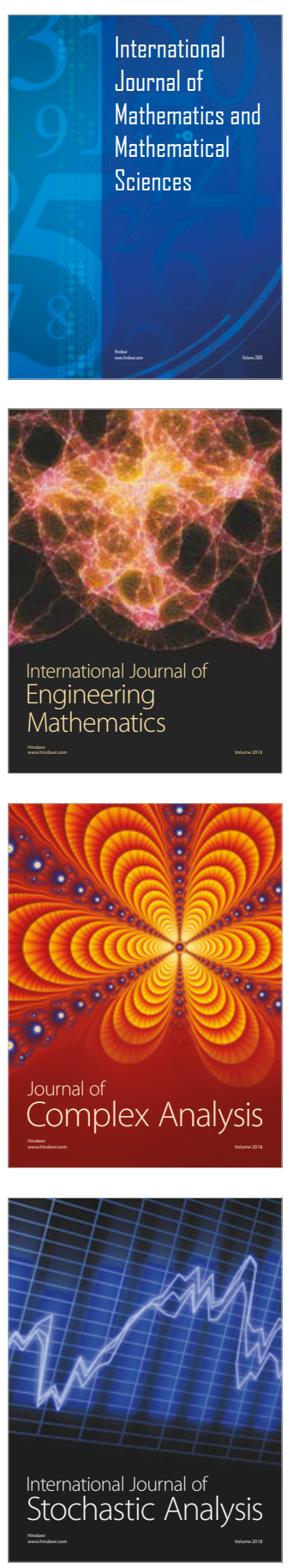
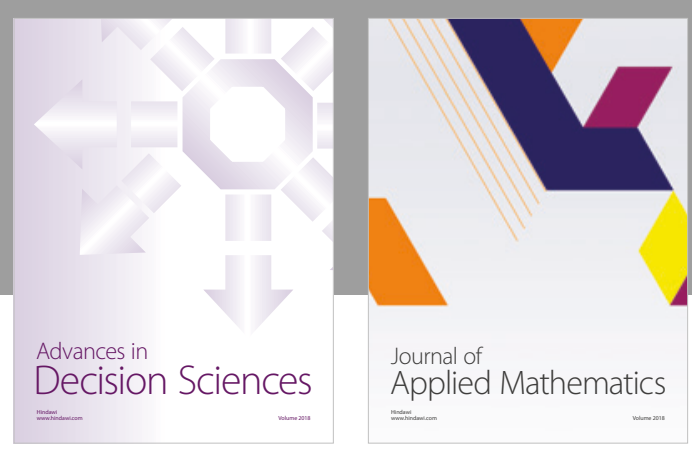

Journal of

Applied Mathematics
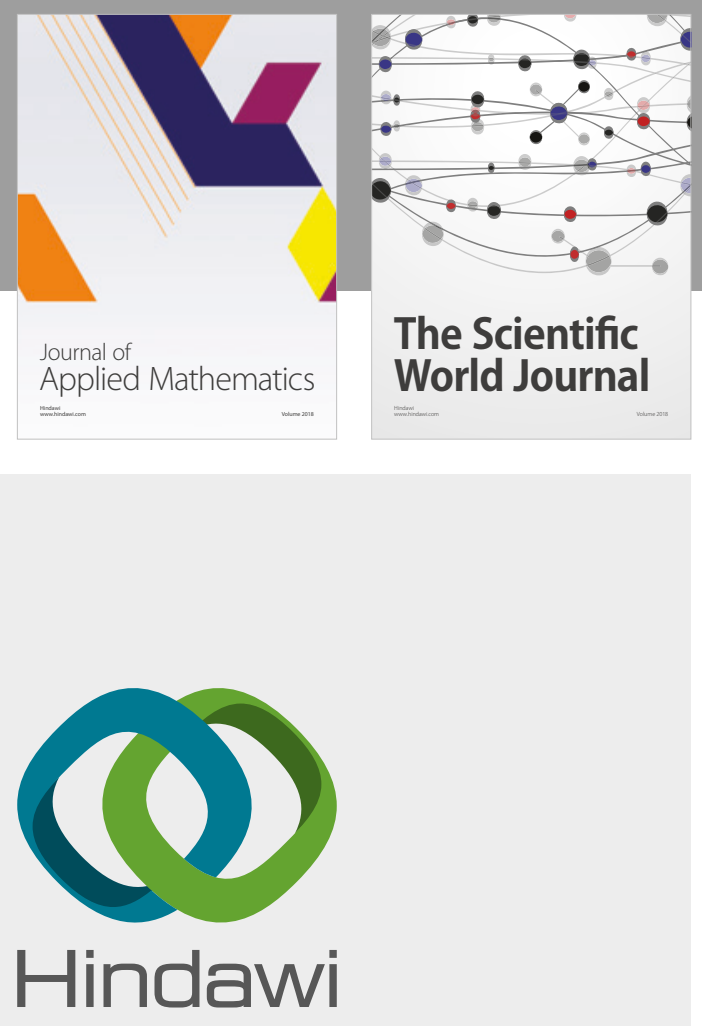

Submit your manuscripts at

www.hindawi.com

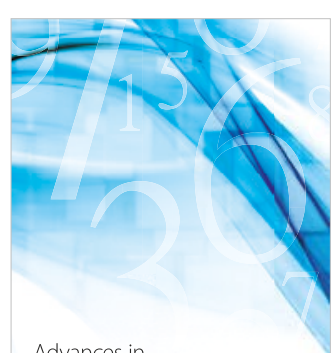

Advances in
Numerical Analysis
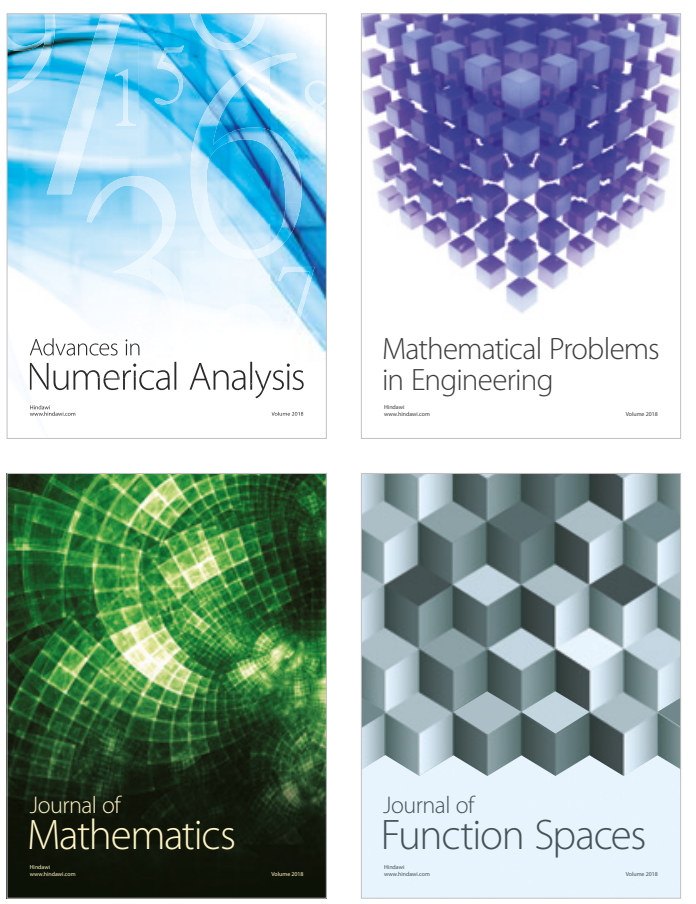

Mathematical Problems in Engineering

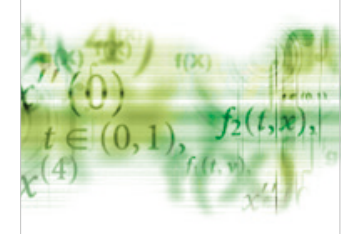

International Journal of

Differential Equations

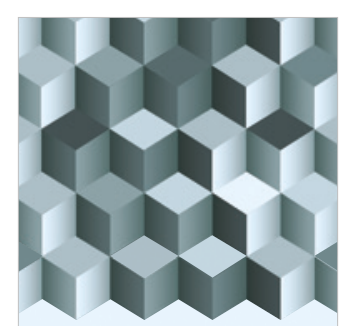

Journal of

Function Spaces
The Scientific

World Journal

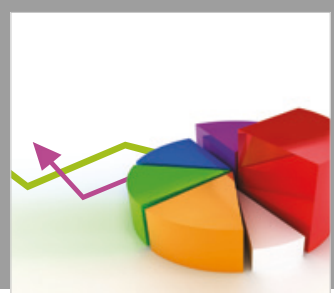

Journal of

Probability and Statistics
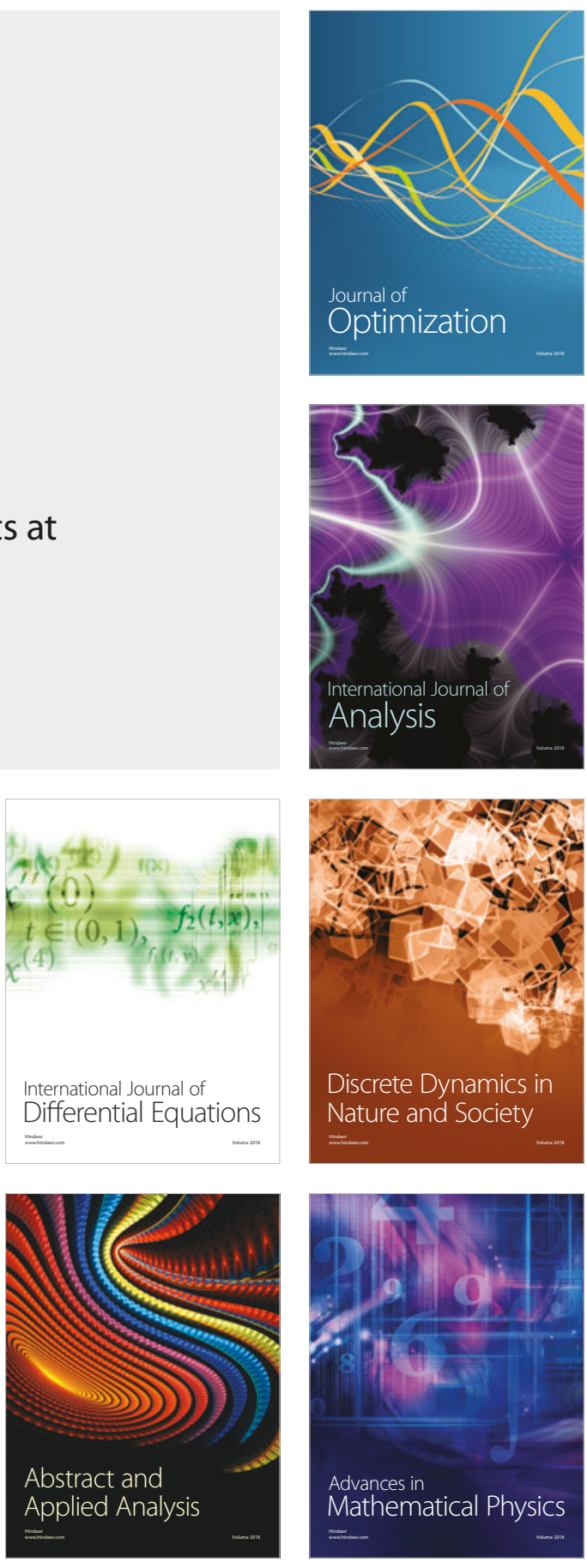